\title{
Systemic lupus erythematosus associated with type 4 renal tubular acidosis: a case report and review of the literature
}

\author{
Haldane Porteous ${ }^{1 *}$, Nadia Morgan²${ }^{2}$ Julio Lanfranco ${ }^{1}$, Monica Garcia-Buitrago ${ }^{3}$, Larry Young ${ }^{4}$ and Oliver Lenz ${ }^{5}$
}

\begin{abstract}
Introduction: Type 4 renal tubular acidosis is an uncommon clinical manifestation of systemic lupus erythematosus and has been reported to portend a poor prognosis. To the best of our knowledge, this is the first case report which highlights the successful management of a patient with systemic lupus erythematosus complicated by type 4 renal tubular acidosis who did not do poorly.

Case presentation: A 44-year-old Hispanic woman developed a non-anion gap hyperkalemic metabolic acidosis consistent with type 4 renal tubular acidosis while being treated in the hospital for recently diagnosed systemic lupus erythematosus with multi-organ involvement. She responded well to treatment with corticosteroids, hydroxychloroquine and mycophenolate mofetil. Normal renal function was achieved prior to discharge and remained normal at the patient's one-month follow-up examination.
\end{abstract}

Conclusion: This case increases awareness of an uncommon association between systemic lupus erythematosus and type 4 renal tubular acidosis and suggests a positive impact of early diagnosis and appropriate immunosuppressive treatment on the patient's outcome.

\section{Introduction}

Inability of the kidney either to excrete sufficient net acid or to retain sufficient bicarbonate results in a group of disorders known as renal tubular acidoses (RTAs) [1]. These are normal anion gap hyperchloremic acidoses. In the traditional classification, type 4 is the only variant associated with hyperkalemia. Compared to the other distal RTAs, in type 4 RTA, the collecting duct fails to excrete both protons and potassium. Such a scenario arises when there is a quantitative or qualitative aldosterone deficiency or a genetic or acquired molecular defect in the relevant transporters. Aldosterone activity is necessary for adequate sodium reabsorption by the epithelial sodium channels. These channels are located on the luminal surface of principal cells in the terminal portions of the nephron. Under normal conditions, they generate a lumen-negative potential, which is essential for potassium and proton secretion [2].

\footnotetext{
* Correspondence: hporteous@med.miami.edu

'Department of Internal Medicine, University of Miami/Jackson Memorial

Hospital, 1611 NW 12th Avenue, Miami, FL 33136, USA

Full list of author information is available at the end of the article
}

RTA is a rare complication of systemic lupus erythematosus (SLE) and can pose a diagnostic dilemma [3]. If inappropriately treated, chronic serum acidity ensues, predisposing to growth retardation, nephrolithiasis, bone disease, chronic kidney disease and even end-stage renal disease. Type 4 RTA is less commonly associated with SLE than type 1 . Patients with type 4 RTA usually have higher SLE disease activity index (SLEDAI) scores [4].

We report a case of a patient with a high SLEDAI score and type 4 RTA secondary to SLE who received prompt and appropriate treatment and did not do poorly.

\section{Case presentation}

A 44-year-old Hispanic woman presented to the hospital with a six-month history of generalized weakness, weight loss of 40 pounds over a four-month period and a two-week history of progressively worsening dyspnea. She had had hypertension for five years for which she was being treated with lisinopril but had been noncompliant for over three years because of financial constraints. The patient denied any alcohol or illicit drug use and was a lifelong non-smoker.

\section{Biomed Central}


On admission, her blood pressure was 102/66 mm/Hg, her temperature was $37^{\circ} \mathrm{C}$, her respiratory rate was 24 breaths/minute, her oxygen saturation level was $92 \%$ on room air and her pulse rate was 88 beats/minute. A physical examination revealed an ill-looking woman with mucosal pallor, generalized wasting and nontender, rubbery axillary and inguinal lymphadenopathy. There was no evidence of cyanosis, digital clubbing, pitting edema, skin rash or joint deformities. Her abdomen was mildly distended but non-tender, with no organomegaly detected. Dullness to percussion and decreased breath sounds over the left base were noted on the respiratory system examination. The cardiovascular and neurological examinations were unremarkable.

Initial laboratory investigations (Table 1) revealed anemia, leukopenia, elevated blood urea nitrogen and elevated serum creatinine. Urinalysis showed trace proteinuria. Chest radiography revealed bilateral pleural effusions that were determined to be exudative in nature on the basis of thoracocentesis. There was a high index of suspicion for malignancy; however, the results of chest, abdomen and pelvis computed tomography scans and an axillary lymph node biopsy did not confirm this. Human immunodeficiency virus and tuberculin skin tests were negative.

On day four of admission, she developed acute inflammatory arthritis of the elbows and knees. A serological workup revealed high anti-nuclear antibody, anti-double-stranded DNA antibody and anti-Smith antibody titers, with low complement 3 levels. An active sediment was noted on the basis of urinalysis (Table 2). The patient's renal impairment persisted, and her glomerular filtration rate was estimated to be $53 \mathrm{ml} / \mathrm{min} / 1.73 \mathrm{~m}^{2}$. A review of blood results since admission showed evidence of documented leukopenia on more than two occasions.

On day 5 of admission, the patient experienced dyspnea and pleuritic chest pain. Reaccumulated pleural effusions were noted on a chest radiograph, and an echocardiogram showed evidence of pericardial effusion. Arterial blood gas interpreted in conjunction with a corresponding basal

\begin{tabular}{|c|c|c|}
\hline Hemoglobin, $6.6 \mathrm{~g} / \mathrm{dl}$ & & $\mathrm{Na}^{+}, 131 \mathrm{mM} / \mathrm{l}$ \\
\hline Hematocrit, 20.9\% & & $\mathrm{K}^{+}, 5.7 \mathrm{mM} / \mathrm{l}$ \\
\hline Platelets, $544 \times 10^{9} / 1$ & & $\mathrm{Cl}^{-}, 105 \mathrm{mM} / \mathrm{l}$ \\
\hline \multirow{4}{*}{$\begin{array}{l}\text { White blood cell } \\
\text { count, } \\
3.5 \times 10^{9} / 1\end{array}$} & Neutrophils, $80.4 \%$ & $\mathrm{HCO}_{3}, 18 \mathrm{mM} / \mathrm{l}$ \\
\hline & $\begin{array}{l}\text { Lymphocytes, } \\
16.0 \%\end{array}$ & $\begin{array}{l}\text { Blood urea nitrogen, } \\
60 \mathrm{mg} / \mathrm{dl}\end{array}$ \\
\hline & Monocytes, $2.1 \%$ & Creatinine, $1.69 \mathrm{mg} / \mathrm{dl}$ \\
\hline & Eosinophils, $0.3 \%$ & \\
\hline
\end{tabular}

\section{Table 2 Urinalysis results from day 4 of admission}

\begin{tabular}{ll}
\hline pH 5 & $\begin{array}{l}\text { White blood cell count, 16 per high } \\
\text { power field }\end{array}$ \\
24-hour urinary protein, & Hyaline cast, zero to two per high- \\
$0.81 \mathrm{~g} /$ day & power field \\
Red blood cell count, 27 per & $\begin{array}{l}\text { Squamous epithelial cells, one per } \\
\text { high-power field }\end{array}$ \\
\hline
\end{tabular}

metabolic panel (Table 3) revealed the presence of a nonanion gap hyperkalemic metabolic acidosis consistent with type 4 RTA. Analysis of morning serum sample showed a serum aldosterone level less than $1 \mathrm{ng} / \mathrm{dl}$.

The renal ultrasound obtained showed normal kidney morphology and no evidence of nephrolithiasis. A renal biopsy was done, which revealed diffuse global proliferative and membranous glomerulonephritis. This was consistent with lupus nephritis Renal Pathology Society/ International Society of Nephrology 2003 class IV-G(A) and $\mathrm{V}$, moderate activity index $9 / 24$, minimal chronicity index 1/12; minimal tubulointerstitial fibrosis and acute tubular necrosis (Figure 1).

She was diagnosed with SLE complicated by a generalized lupus flare, with a SLEDAI score of 29. Overall during this single admission, she demonstrated six of the 11 American College of Rheumatology criteria used in the diagnosis of SLE.

The patient was treated with a course of hydroxychloroquine and intravenous methylprednisone $1 \mathrm{~g}$ daily for three days. Thereafter she was placed on a prednisone, mycophenolate mofetil and hydroxychloroquine regimen. Complete resolution of the renal impairment (Figures 2 and 3) and type 4 RTA (Figure 4) was achieved. She was discharged after 19 days to follow-up in the Rheumatology and Nephrology clinics. Her renal function remained normal at the one-month follow-up clinic visit.

\section{Discussion}

The clinical manifestations of SLE are many and varied, making it a plausible component of many differential diagnoses [5]. It is one of several diseases known as "the great imitators" because it often mimics other diseases. RTA is a medical condition that involves an accumulation of acid in the body due to a failure of the kidneys to appropriately acidify the urine [1].

Table 3 Arterial blood gas and basic metabolic panel results from day $\mathbf{5}$ of admission

\begin{tabular}{ll}
\hline $\mathrm{pH} 7.34$ & $\mathrm{Na}^{+}, 145 \mathrm{mM} / \mathrm{l}$ \\
$\mathrm{HCO}_{3}, 14 \mathrm{mM} / \mathrm{l}$ & $\mathrm{K}^{+}, 5.5 \mathrm{mM} / \mathrm{l}$ \\
$\mathrm{CO}_{2}, 26 \mathrm{mmHg}$ & $\mathrm{Cl}^{-}, 120 \mathrm{mM} / \mathrm{l}$ \\
$\mathrm{pO}_{2}, 96 \mathrm{mmHg}$ & $\mathrm{HCO}_{3}, 19 \mathrm{mM} / \mathrm{l}$ \\
& Blood urea nitrogen, $67 \mathrm{mg} / \mathrm{dl}$ \\
& Creatinine, $1.09 \mathrm{mg} / \mathrm{dl}$ \\
\hline
\end{tabular}




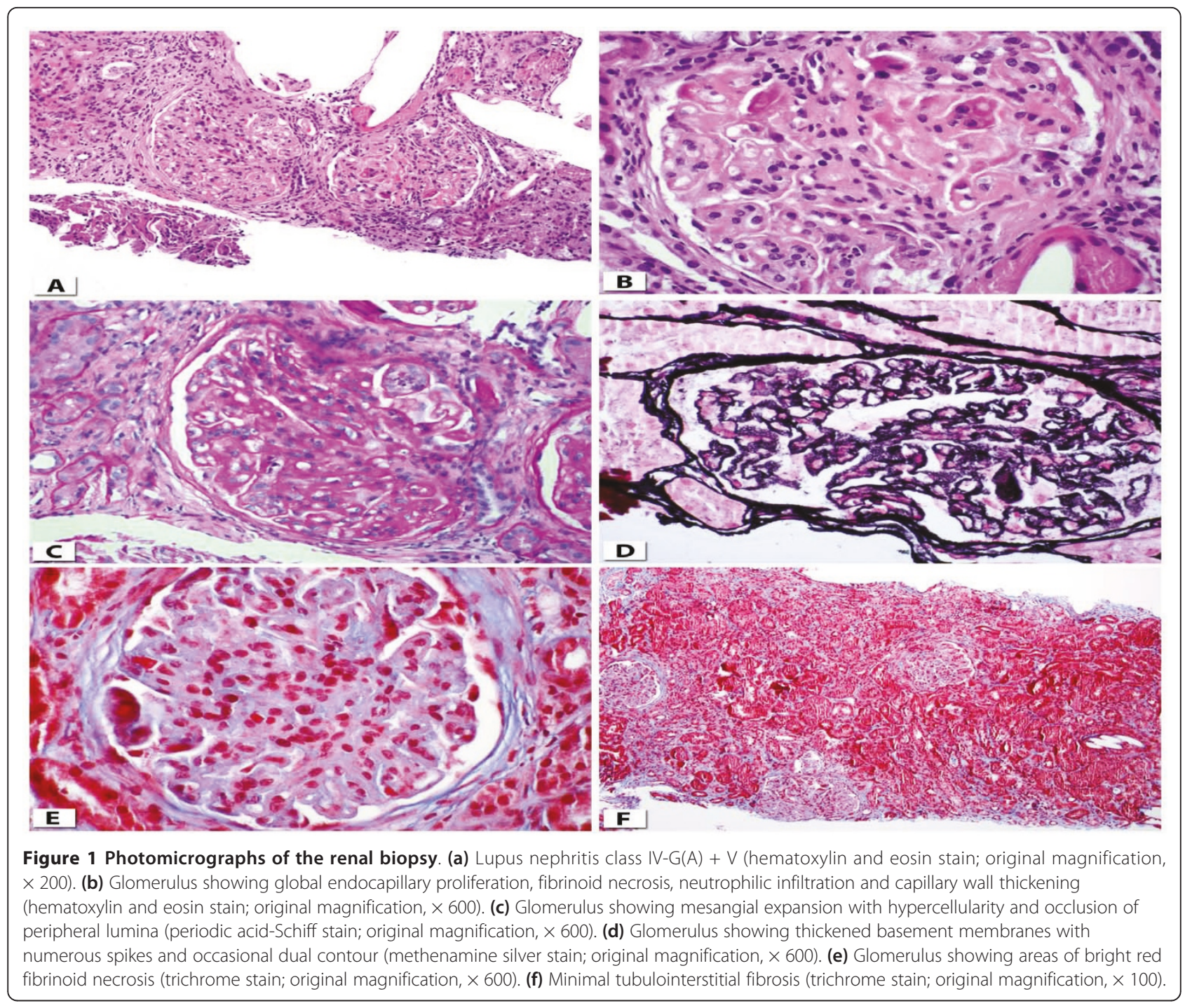

As many as $60 \%$ of adults with SLE develop overt renal abnormalities, and $10 \%$ to $15 \%$ of patients with lupus nephritis progress to end-stage renal failure [6]. RTA is rarely associated with SLE and, if present, is more commonly of the type 1 than the type 4 variety [4]. It likely represents the consequence of significant tubulointerstitial damage, which should signal the need for rapid treatment of the underlying lupus nephritis to avoid future renal insufficiency [7].

In the setting of a hyperkalemic normal anion gap metabolic acidosis and a urine $\mathrm{pH}$ less than 5.5, the clinician should have a high index of suspicion for the presence of type 4 RTA. Conversely, a diagnosis of incomplete type 1 RTA may be entertained in patients with hyperkalemia and a urine $\mathrm{pH}$ which is persistently greater than 5.5 [8].

The presence of type 4. RTA can be confirmed by calculating the transtubular potassium concentration gradient
(TTKG) [9]. TTKG is an index of the potassium-secreting activity of the cells in the distal tubule. In normal individuals, hyperkalemia is associated with increased aldosterone secretion and distal potassium excretion, leading to a high TTKG level (usually greater than 10). A TTKG level less than 7 is highly suggestive of hyporeninemic hypoaldosteronism probably due to tubulointerstitial damage [10]. Our patient's calculated TTKG was 5.3 (Table 4).

Other causes of type 4 RTA were ruled out. Our patient had a normal cortisol level of $14.4 \mu \mathrm{g} / \mathrm{dl}$, making adrenal insufficiency unlikely. She divulged no history of taking non-steroidal anti-inflammatory drugs, potassiumsparing diuretics, heparin, trimethoprim or angiotensin receptor blocker use. A history of angiotensin-converting enzyme inhibitor use was elicited; however, she was completely non-compliant with the same for the past three years, making this an unlikely cause. 

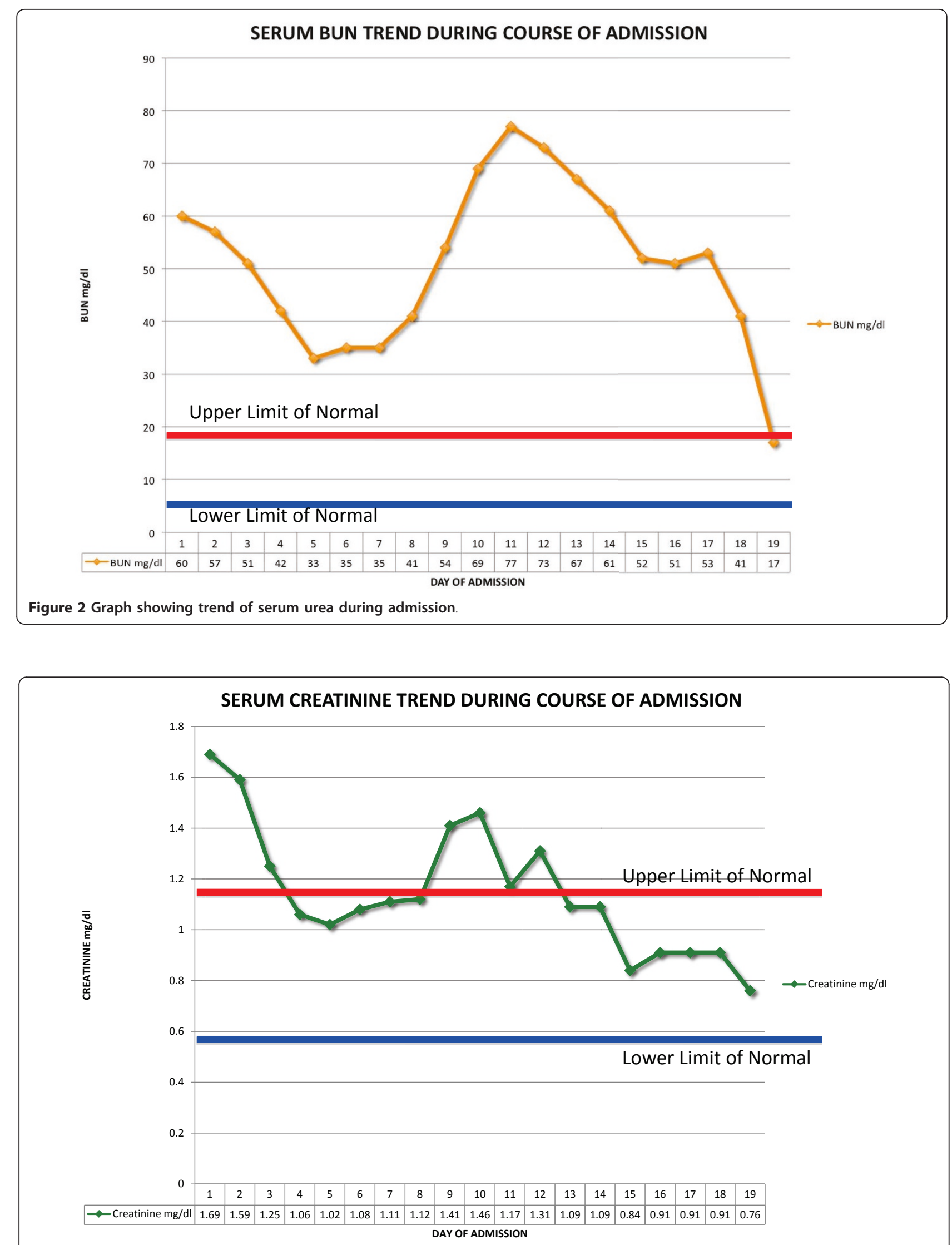

Figure 3 Graph showing trend of serum creatinine during admission. 


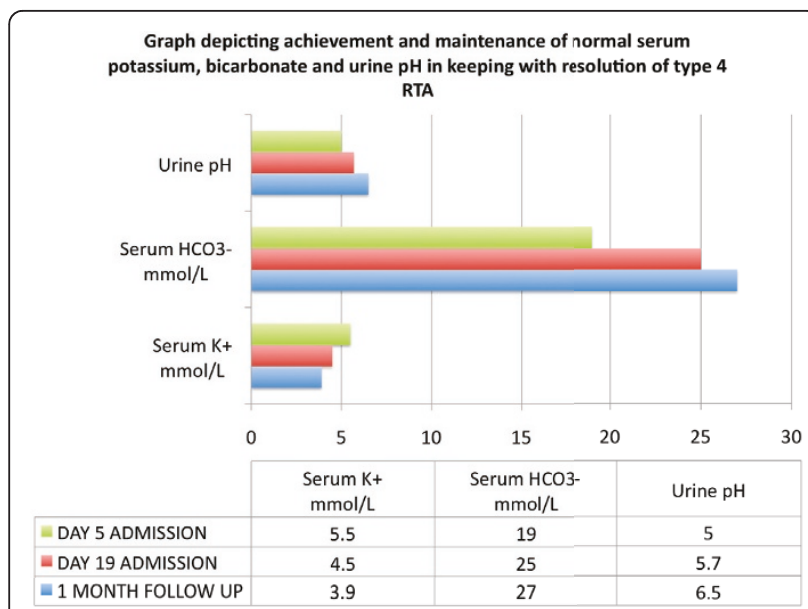

Figure 4 Graph depicting achievement and maintenance of normal serum potassium, bicarbonate and urine $\mathrm{pH}$ in keeping with resolution of type 4 renal tubular acidosis.

Li et al. [4] noted the association between type 4 RTA and SLE in patients with high SLEDAI scores. They found that the degree of hyperkalemia was correlated with a high SLEDAI score and that these patients had a poor outcome of chronic renal insufficiency requiring hemodialysis at admission or resulting in death. Patients with type 4 RTA have more extensive tubular damage stemming from aggressive nephritis associated with more aggressive systemic manifestations of SLE. Thus, the presence of type 4 RTA is an indicator of more aggressive SLE. In our patient, hyperkalemia and a high SLEDAI score of 29 were noted; however, she did not do poorly. Her type 4 RTA and significant renal impairment resolved completely after two weeks of appropriate therapy.

\section{Conclusion}

To the best of the authors' knowledge this is the first reported case of a patient with SLE who had a high SLEDAI score and type 4 RTA secondary to lupus nephritis, yet did not do poorly. This case emphasizes the fact that early diagnosis and appropriate treatment can indeed result in the desired positive outcome.

\section{Consent}

Written informed consent was obtained from our patient for publication of this case

\section{Table 4 Calculation of transtubular gradient}

\begin{tabular}{ll}
\hline Urine sodium, $59 \mathrm{mM} / \mathrm{l}$ & Transtubular gradient \\
Urine potassium, $38 \mathrm{mM} / \mathrm{l}$ & Urine K/plasma K \\
Urine osmolality, $405 \mathrm{mOsm} / \mathrm{kg}$ & Urine osmolality/plasma osmolality \\
Plasma potassium, $5.1 \mathrm{mM} / \mathrm{l}$ & \\
Plasma osmolality, $288 \mathrm{mOsm} / \mathrm{kg}$ & Patient's transtubular gradient = 5.3 \\
\hline
\end{tabular}

report and any accompanying images. A copy of the written consent is available for review by the Editor-inChief of this journal.

\section{Abbreviations}

RTA: renal tubular acidosis; SLE: systemic lupus erythematosus; SLEDAI: systemic lupus erythematosus disease activity index; TTKG: transtubular potassium gradient.

\section{Acknowledgements}

We thank J Radkey of the Department of Pathology, Jackson Memorial Hospital, for his help in preparing and interpreting the renal biopsy.

\section{Author details}

${ }^{1}$ Department of Internal Medicine, University of Miami/Jackson Memorial Hospital, 1611 NW 12th Avenue, Miami, FL 33136, USA. ²Department of Internal Medicine, State University of New York Downstate Medical Center, 450 Clarkson Avenue, Brooklyn, NY 11203, USA. Department of Pathology, University of Miami/Jackson Memorial Hospital, 1611 NW 12th Avenue, Miami, FL 33136, USA. ${ }^{4}$ Department of Rheumatology, Miami Veterans Affairs Medical Center, 1201 NW 16th Street, Miami, FL 33125, USA. ${ }^{5}$ Department of Nephrology, University of Miami/Jackson Memorial Hospital, 1611 NW 12th Avenue, Miami, FL 33136, USA.

\section{Authors' contributions}

HP and NM collected the data and drafted the manuscript. HP and JL contributed to the treatment of the patient. $L Y$ and $O L$ participated in critical revision of the report and helped draft the manuscript. All authors read and approved the final manuscript.

\section{Competing interests}

The authors declare that they have no competing interests.

Received: 1 May 2010 Accepted: 24 March 2011

Published: 24 March 2011

\section{References}

1. Laing CM, Toye AM, Capasso G, Unwin RJ: Renal tubular acidosis: developments in our understanding of the molecular basis. Int J Biochem Cell Biol 2005, 37:1151-1161.

2. Karet FE: Mechanisms in hyperkalemic renal tubular acidosis. $J$ Am Soc Nephrol 2009, 20:251-254.

3. Caruana RJ, Barish CF, Buckalew VM Jr: Complete distal renal tubular acidosis in systemic lupus: clinical and laboratory findings. Am J Kidney Dis 1985, 6:59-63.

4. Li SL, Liou LB, Fang FT, Tsai WP: Symptomatic renal tubular acidosis (RTA) in patients with systemic lupus erythematosus: an analysis of six cases with new association of type 4 RTA. Rheumatology 2005, 44:1176-1180.

5. Rahman A, Isenberg DA: Systemic lupus erythematosus. N Engl J Med 2008, 358:929-939.

6. Cameron JS: Lupus nephritis. J Am Soc Nephrol 1999, 10:413-424.

7. Gur H, Kopolovic Y, Gross DJ: Chronic predominant interstitial nephritis in a patient with systemic lupus erythematosus: a follow up of three years and review of the literature. Ann Rheum Dis 1987, 46:617-623.

8. Bagga A, Sinha A: Evaluation of renal tubular acidosis. Indian J Pediatr 2007, 74:679-686.

9. Ethier JH, Kamel KS, Magner PO, Lemann J Jr, Halperin ML: The transtubular potassium concentration in patients with hypokalemia and hyperkalemia. Am J Kidney Dis 1990, 15:309-315.

10. West ML, Marsden PA, Richardson RM, Zettle RM, Halperin ML: New clinical approach to evaluate disorders of potassium excretion. Miner Electrolyte Metab 1986, 12:234-238.

\section{doi:10.1186/1752-1947-5-114}

Cite this article as: Porteous et al.: Systemic lupus erythematosus associated with type 4 renal tubular acidosis: a case report and review of the literature. Journal of Medical Case Reports 2011 5:114. 